
\title{
$\begin{array}{ll}\text { Research Square } & \begin{array}{l}\text { Preprints are preliminary reports that have not undergone peer review. } \\ \text { They should not be considered conclusive, used to inform clinical practice, } \\ \text { or referenced by the media as validated information. }\end{array}\end{array}$
}

\section{The Extent and Barriers in Providing Pharmaceutical Care Services by Community Pharmacists in Malaysia: a Cross-sectional Study}

\author{
Pengyeow Loh ( $\nabla$ lohpengyeow@gmail.com) \\ Taylor's University - Lakeside Campus: Taylor's University https://orcid.org/0000-0002-1912-5570 \\ Siew Siang Chua \\ School of Pharmacy, Faculty of Health and Medical Sciences, Taylor's University \\ Mahmathi Karuppannan \\ Department of Pharmacy Practice, Faculty of Pharmacy, University of Technology MARA
}

\section{Research article}

Keywords: community pharmacists, pharmaceutical care, pharmacy services, barriers

Posted Date: December 29th, 2020

DOI: https://doi.org/10.21203/rs.3.rs-135729/v1

License: (c) (i) This work is licensed under a Creative Commons Attribution 4.0 International License. Read Full License

Version of Record: A version of this preprint was published at BMC Health Services Research on August 16th, 2021. See the published version at https://doi.org/10.1186/s12913-021-06820-7. 


\section{Abstract}

Background: Since the introduction of pharmaceutical care concept by Hepler and Strand in 1990, community pharmacists worldwide have been realigning their roles from being product-focused to patient-orientated to improve patient's quality of life. The objectives of this study were to determine the type of services, with emphasis on the extent of pharmaceutical care services provided by community pharmacists and the barriers in providing such services in Malaysia.

Methods: A cross-sectional observational study was conducted using an online questionnaire. Community pharmacists in Malaysia were invited to participate in the study via emails. The questionnaire was structured based on the Malaysian Community Pharmacy Benchmarking Guidelines, the five practice principles of pharmaceutical care by the American Pharmacists Association and other studies. The online questionnaire was opened for 6 months, from April to September 2018. A reminder to participate was sent via email to the community pharmacists every fortnight.

Results: A total of 420 community pharmacists responded to the online questionnaire. Besides essential services such as treatment for minor illness, medicine dispensing and counselling, most of the respondents were providing health screening and monitoring (99.5\%), selection and recommendation of health supplements (90.5\%), patient medication review (68.8\%), weight management (52.4\%) and counselling on smoking cessation (51.0\%). More than half (53.3\%) of the respondents reported that they were providing pharmaceutical care services to patients with chronic diseases. Based on the practice principles of pharmaceutical care, the respondents were involved in patients' data collection (23.3\%), medical information evaluation (18.6\%), formulating a drug therapy plan (9.3\%), implementing a drug therapy plan (4.5\%), and monitoring and modifying the plan (18.3\%). Lack of separation between prescribing and dispensing was perceived as the main barrier to the implementation of pharmaceutical care services by a majority of the respondents (84.0\%).

Conclusions: The present study found that pharmaceutical care services provided by community pharmacists in Malaysia were inadequate in comparison with international practice principles. Areas that need improvement included collaboration with patients' other health care providers; more proactive management of patient's medicine regimen; having proper patient monitoring and follow-up mechanisms, and documentation.

\section{Background}

Since the introduction of the pharmaceutical care philosophy by Hepler and Strand in 1990, community pharmacists worldwide have been urged by the respective governments and professional bodies, to shift their roles from being product-focused to patient-orientated, to achieve definite outcomes that improve a patient's quality of life [1]. The American Pharmacists Association (APhA) developed five principles on the practice of pharmaceutical care to ensure positive outcomes for patients. These five principles included: patients' data collection; medical information evaluation; formulating a drug therapy plan; implementing the plan; monitoring and modifying the plan [2].

Studies on pharmaceutical care services provided by community pharmacists found that such services improved adherence to medications for chronic diseases such as hypertension, osteoporosis and hyperlipidaemia [3-5]. The optimisation of medication use had also led to a reduction in health care cost [4, 5]. Patients receiving pharmaceutical care services showed improved health indices such as significant decreases in glycated haemoglobin (HbA1c) level, systolic and diastolic blood pressure [6-9], better knowledge of the disease and improvement in certain components of health-related quality of life [8], as well as experienced a reduction in length of hospital stay and a lower rate of hospital readmission $[10,11,12]$.

However, various studies had raised concern on the under-utilisation of community pharmacists in Malaysia in providing optimal health care to the general public and contributing to the health care system of the country [13-15]. Community pharmacists in Malaysia were mainly involved in supplying medicines and health supplements, providing advice and treatment for minor health problems, and conducting health screening tests [16], although some also provided health promotion services such as counselling on healthy lifestyles, smoking cessation and weight management $[13,17]$. Thus far, there is a lack of recent studies on the types of pharmacy services provided by community pharmacists nationwide. Besides, studies specifically on pharmaceutical care services provided by community pharmacists in Malaysia, as well as possible barriers for community pharmacists to practise such services are still lacking. Sam et al. concluded that slightly more than half of the patients were satisfied with the pharmaceutical care services provided by a community pharmacist [18]. Another Malaysian study showed positive clinical outcomes of diabetes patients who went through a community pharmacist-based diabetes management programme [7]. However, both studies were limited to only one community pharmacy in Malaysia. Other local studies on pharmaceutical care focused more on counselling provided by community pharmacists $[13,19,20]$. Although medication counselling is an important element of pharmaceutical care and has been shown to have a positive impact on patient medicine use behaviour and adherence [21], this is only a part of the practice principles for pharmaceutical care by APhA [22].

At the time of the present study, there were more than 2,500 community pharmacies in Malaysia [23]. The health care resources in Malaysia are already stretching to the limit. As community pharmacies are easily accessible by the general public, they should be fully utilised in the development and implementation of the health care system in Malaysia. The question is: Are community pharmacists providing adequate pharmaceutical care services which can contribute to the health care system in Malaysia?

Therefore, the main objectives of the present study were to determine the types of services provided by community pharmacists in Malaysia, with emphasis on the extent of pharmaceutical care services and any barriers associated with the provision of such services, from the pharmacists' perspectives. The findings of this study will enable health care stakeholders in the country to better understand and plan a more comprehensive health care system in Malaysia. This should involve all health care providers including community pharmacists in the partnership or integration between public and private health sectors [24]. This study will also bring awareness to community pharmacists on areas of pharmacy practice which they need to prioritise or improve to provide better health care. In addition, the insights on perceived barriers by the community pharmacists in the implementation of pharmaceutical care will enable related 
professional bodies to continue engaging with policymakers to develop a better platform for the profession to contribute to the health care system of the country.

\section{Methods}

This was a cross-sectional study which used an online, self-administered questionnaire via Survey Monkey®. The target population was community pharmacists who were working in private community pharmacies on a full-time basis in the country. Pharmacists who were working on part-time basis as locum pharmacists, or only in the administration or wholesale department of a community pharmacy, or a community pharmacy located inside a hospital premise, were excluded based on a screening question placed at the beginning of the questionnaire.

Using Raosoft@ sample size calculator (http://www.raosoft.com /samplesize.html), with $95 \%$ confidence level, $5 \%$ margin of errors, a study population size of 2,278 and assuming that the prevalence of pharmaceutical care provision was $50 \%$, the calculated sample size was 329 .

A questionnaire was developed based on the Community Pharmacy Benchmarking Guideline [25] as well as the five practice principles of pharmaceutical care [2] and from other studies in the literature $[13,16,17,26]$. The questionnaire used in this study was developed specifically for this study and provided in the Additional File 1.

The evaluation of pharmaceutical care services provided was based on the five practice principles of pharmaceutical care by the American Pharmacists Association (APhA) [2]: (1) Patients' data collection, (2) Medical information evaluation, (3) Formulating a drug therapy plan, (4) Implementing a drug therapy plan, (5) Monitoring and modifying the plan. These five practice principles were evaluated using 15 sub-questions to best match the definition of each principle by APhA [2].

Ten practising community pharmacists with 10 to 20 years of working experience were consulted on which sub-questions could be used to fulfil each of the pharmaceutical care practice principle by APhA [2]. The response and feedback were analysed and the research team concluded that the community pharmacists needed to carry out all the sub-questions under each of the practice principles to be considered as having fulfilled the practice principle concerned (Additional File 2).

Content validity and clarity of the questionnaire were reviewed and assessed by five practising community pharmacists who have a minimum of 10 years working experience. The questionnaire was modified based on their feedback and uploaded online using Survey Monkey ${ }^{\circledR}$. A pilot study was conducted on 20 community pharmacists. These community pharmacists consisted of those in Northern (5), Central (6), Southern (3), East Coast (2) regions of Peninsular Malaysia, and from East Malaysia (4). These community pharmacists were requested not to participate in the main study. The results of the pilot study were excluded from the main study.

A list of email contacts of registered community pharmacists in Malaysia was compiled with the help of the Malaysian Pharmaceutical Society (MPS). Community pharmacists were contacted via email to participate in this study. The study was conducted using an online survey. When the invited pharmacists clicked the survey link included in the emails sent to them, they would be connected to the information sheet which contained information about the study, estimated time to complete the survey, participants' rights to withdraw from the study at any time, including withdrawal of any information provided, and the assurance of their confidentiality. If the invited pharmacists agreed to participate in the study, they were required to click a checkbox for consent before they could proceed to do the questionnaire. The study had been reviewed and approved by the Human Ethics Committee of Taylor's University Malaysia (reference number: HEC 2018/002).

The anonymity of the respondents was preserved in the study using the "anonymous responses collector" option from Survey Monkey® so as not to track and store the respondents' information. The "multiple responses" option in Survey Monkey ${ }^{\circledR}$ was turned off to allow only one response per browser or email address, thus minimising multiple responses from a single respondent. The online questionnaire was opened for 6 months, from April to September 2018. During these 6 months, a reminder to participate was sent via email to the community pharmacists every fortnight.

\section{Data analysis}

All data were entered and analysed using the Statistical Package for the Social Science (SPSS) version 21 (IBM Corp, Armonk, New York). Descriptive statistics were performed on all variables. For numeric data, the mean (standard deviation, SD) and median (interquartile range, IQR) were generated. Any possible associations between variables were first tested using univariate chi-square analysis and variables that produced p-value equal to or less than 0.25 were further tested using binary logistic regression under the generalised linear model function [27]. A p-value of less than 0.05 was considered as statistically significant. A small Chi-square value with $p>0.05$ from Hosmer-Lemeshow Goodness of Fit test indicates that the model fit is acceptable [28].

Barriers in implementing pharmaceutical care were graded based on a 6-point Likert-like scale, ranging from strongly disagree (0) to strongly agree (5). Mean score (SD) were calculated for each barrier statement [29]. These responses were then collapsed into three groups: 'strongly disagree and disagree', 'slightly disagree and slightly agree' and 'agree and strongly agree' to ease interpretation of results [29, 30].

\section{Results}

From the list of 2,278 community pharmacists, 52 responded that they had stopped practising as community pharmacists while two invalid email addresses were returned, leaving a total of 2,224 community pharmacists. The online questionnaire survey was closed after 6 months with 420 completed questionnaires. This gives a response rate of $18.9 \%(420 / 2,224)$ but meets the minimum required number of 329 from the Raosoft $\circledast$ calculation. Characteristics of the respondents are as shown in Table 1. 
Table 1

Characteristics of respondents and practice premises $(\mathrm{N}=420)$

\begin{tabular}{|c|c|}
\hline Characteristics & Number of respondents (\%) \\
\hline \multicolumn{2}{|l|}{ Gender } \\
\hline Female & $264(62.9 \%)$ \\
\hline Male & $156(37.1 \%)$ \\
\hline \multicolumn{2}{|l|}{ Age group } \\
\hline $21-29$ & 80 (19.0\%) \\
\hline $30-39$ & $150(35.7 \%)$ \\
\hline $40-49$ & $118(28.1 \%)$ \\
\hline $50-59$ & $57(13.6 \%)$ \\
\hline 60 and above & $15(3.6 \%)$ \\
\hline \multicolumn{2}{|l|}{ Ethnic group } \\
\hline Malay & $84(20.0 \%)$ \\
\hline Chinese & $309(73.6 \%)$ \\
\hline Indian & $16(3.8 \%)$ \\
\hline Others ${ }^{a}$ & $11(2.6 \%)$ \\
\hline \multicolumn{2}{|c|}{ Highest pharmacy related education level } \\
\hline Basic pharmacy degree & $399(95.0 \%)$ \\
\hline Master's degree & $21(5.0 \%)$ \\
\hline Ph.D in Pharmacy & $0(0.0 \%)$ \\
\hline \multicolumn{2}{|l|}{ Country of basic degree } \\
\hline Malaysia & $244(58.1 \%)$ \\
\hline Overseas & $176(41.9 \%)$ \\
\hline \multicolumn{2}{|l|}{ Years of practice in Malaysia } \\
\hline Less than 5 & $124(29.5 \%)$ \\
\hline 5 to 9 & 77 (18.3\%) \\
\hline 10 to 14 & $53(12.6 \%)$ \\
\hline 15 to 19 & $67(16.0 \%)$ \\
\hline 20 to 24 & $62(14.8 \%)$ \\
\hline 25 and above & $37(8.8 \%)$ \\
\hline \multicolumn{2}{|l|}{ Type of Employment } \\
\hline Self-employed / Shareholder & $187(44.5 \%)$ \\
\hline Full time employee & $233(55.5 \%)$ \\
\hline \multicolumn{2}{|l|}{ Premise location (state) } \\
\hline Selangor & $94(22.4 \%)$ \\
\hline Johor & $55(13.1 \%)$ \\
\hline Kuala Lumpur & $51(12.1 \%)$ \\
\hline Sarawak & $45(10.7 \%)$ \\
\hline Penang & $37(8.8 \%)$ \\
\hline Sabah & $30(7.1 \%)$ \\
\hline Perak & $27(6.4 \%)$ \\
\hline Negeri Sembilan & $21(5.0 \%)$ \\
\hline Pahang & $15(3.6 \%)$ \\
\hline
\end{tabular}

Page $4 / 16$ 


\begin{tabular}{|ll|}
\hline Characteristics & Number of respondents (\%) \\
\hline Malacca & $13(3.1 \%)$ \\
\hline Kedah & $10(2.4 \%)$ \\
\hline Telantan & $7(1.7 \%)$ \\
\hline Putrajaya & $7(1.7 \%)$ \\
\hline Perlis & $5(1.2 \%)$ \\
\hline Labuan & $2(0.5 \%)$ \\
\hline Number of prescriptions/year & $1(0.2 \%)$ \\
\hline 0 & $21(5.0 \%)$ \\
\hline $1-100$ & $347(82.6 \%)$ \\
\hline $101-1,000$ & $45(10.7 \%)$ \\
\hline $1,001-3000$ & $6(1.4 \%)$ \\
\hline 10,000 and above & $1(0.2 \%)$ \\
\hline
\end{tabular}

\section{Types of pharmacy services provided}

Figure 1 shows the types of pharmacy services provided by the respondents regularly, besides essential services such as response to minor illnesses, medicine dispensing and medication counselling, as stipulated in the Community Pharmacy Benchmarking Guideline [25].

Almost all the respondents (99.5\%) were providing at least one type of health screening and monitoring, with measurement of blood pressure (99.3\%), blood glucose (97.9\%), cholesterol (74.5\%) levels as the most common services.

Among the respondents who offered the selection and recommendation of health supplements for general health, only $15.8 \%$ (60) have been certified with Complementary Medicine Education (CMed). Whereas, of the respondents who were providing smoking cessation program to assist their clients to quit smoking, 53.7\% (115) were Certified Smoking Cessation Service Providers (CSCSP).

\section{Factors associated with types of pharmacy services provided}

A total of eleven potential factors which might be associated with the types of pharmacy services provided were analysed using binary logistic regression: gender, age group, ethnic group, education level, local or overseas graduate, CSCSP, MyHealth MyWeight, Harm Reduction Program, Diabetes Medicine Therapy Adherence Clinic (DMTAC) certified or trained, year of practice and type of employment. Only factors that were significantly associated with the types of pharmacy services provided are shown in Table 2. 
Table 2

Factors associated with the types of pharmacy services provided $(\mathrm{N}=409)^{\mathrm{a}}$

\begin{tabular}{|c|c|c|c|c|c|c|c|}
\hline \multirow[t]{2}{*}{ Services } & \multirow[t]{2}{*}{ Factors } & \multirow[t]{2}{*}{ Characteristics } & \multirow{2}{*}{$\begin{array}{l}\text { Frequency } \\
(\%)\end{array}$} & \multirow[t]{2}{*}{$\begin{array}{l}\text { Odds Ratio }(95 \% \\
\mathrm{Cl})\end{array}$} & \multirow[t]{2}{*}{$\begin{array}{l}\text { Adjusted } p- \\
\text { value }\end{array}$} & \multicolumn{2}{|c|}{$\begin{array}{l}\text { Hosmer-Lemeshow Good of Fit } \\
\text { test }\end{array}$} \\
\hline & & & & & & Chi-square & p-value \\
\hline \multirow[t]{2}{*}{ Home medication review } & \multirow[t]{2}{*}{ Education } & Basic degree & $23(5.9)$ & As reference & \multirow[t]{2}{*}{$0.032^{\star}$} & \multirow[t]{2}{*}{1.986} & \multirow[t]{2}{*}{0.370} \\
\hline & & Master & $4(21.1)$ & $\begin{array}{l}3.728(1.117 \\
12.447)\end{array}$ & & & \\
\hline \multirow[t]{2}{*}{$\begin{array}{l}\text { Multiple medicine } \\
\text { management }\end{array}$} & \multirow[t]{2}{*}{ CSCSP } & Yes & $41(28.5)$ & $\begin{array}{l}1.848(1.137 \\
3.005)\end{array}$ & \multirow[t]{2}{*}{$0.013^{*}$} & \multirow[t]{2}{*}{0.870} & \multirow[t]{2}{*}{0.929} \\
\hline & & No & $50(18.9)$ & As reference & & & \\
\hline \multirow[t]{2}{*}{ Health supplement } & \multirow[t]{2}{*}{ Education } & Basic degree & 357 (91.5) & $\begin{array}{l}4.887(1.699 \\
14.054)\end{array}$ & \multirow[t]{2}{*}{$0.003^{\star *}$} & \multirow[t]{2}{*}{0.742} & \multirow[t]{2}{*}{0.690} \\
\hline & & Master & $13(68.4)$ & As reference & & & \\
\hline \multirow[t]{2}{*}{ Pregnancy test } & \multirow[t]{2}{*}{ Employment } & Self-employed & $71(39.4)$ & $\begin{array}{l}2.803(1.681 \\
4.672)\end{array}$ & \multirow[t]{2}{*}{$<0.001$ ** } & \multirow[t]{2}{*}{8.125} & \multirow[t]{2}{*}{0.322} \\
\hline & & $\begin{array}{l}\text { Full-time } \\
\text { employee }\end{array}$ & $33(14.4)$ & As reference & & & \\
\hline \multirow[t]{8}{*}{ Smoking cessation } & \multirow[t]{2}{*}{ Gender } & Female & $145(56.2)$ & $\begin{array}{l}2.082(1.278 \\
3.392)\end{array}$ & \multirow[t]{2}{*}{$0.003^{\star \star}$} & \multirow[t]{8}{*}{3.582} & \multirow[t]{8}{*}{0.893} \\
\hline & & Male & $65(43.0)$ & As reference & & & \\
\hline & \multirow[t]{2}{*}{ Ethnicity ${ }^{b}$} & Malay & $34(40.5)$ & As reference & $0.022^{\star}$ & & \\
\hline & & Chinese & $167(54.0)$ & $\begin{array}{l}1.936(1.100 \\
3.407)\end{array}$ & & & \\
\hline & CSCSP & Yes & $113(78.5)$ & $\begin{array}{l}8.158(4.731 \\
14.066)\end{array}$ & $<0.001^{\star *}$ & & \\
\hline & & No & $97(36.6)$ & As reference & & & \\
\hline & Employment & Self-employed & $73(40.6)$ & As reference & $0.049 *$ & & \\
\hline & & $\begin{array}{l}\text { Full-time } \\
\text { employee }\end{array}$ & $137(59.8)$ & $\begin{array}{l}1.642(1.003 \\
2.687)\end{array}$ & & & \\
\hline Weight management & Age & Below 40 & $127(56.2)$ & $\begin{array}{l}1.772(1.118 \\
2.809)\end{array}$ & $0.015^{\star}$ & 12.542 & 0.084 \\
\hline & & 40 and above & $89(48.6)$ & As reference & & & \\
\hline & MyHealth & Yes & $60(80.0)$ & $\begin{array}{l}4.892(2.557 \\
9.360)\end{array}$ & $<0.001^{\star *}$ & & \\
\hline & & No & $156(46.7)$ & As reference & & & \\
\hline${ }^{a}$ Eleven respondents from & ethnic groups & were excluded fro & nalysis due & insufficient numb & or statistical & arison & \\
\hline $\begin{array}{l}\mathrm{b} \text { The three major ethnic } \mathrm{g} \\
\text { when compared to Malay }\end{array}$ & $\begin{array}{l}\text { in Malaysia ar } \\
\text { inese }\end{array}$ & Malay, Chinese a & ndians but & dians are not shov & this table a & was no si & association \\
\hline
\end{tabular}

\section{Provision of pharmaceutical care services}

Of the 420 respondents, $53.3 \%$ (224) reported that they were providing pharmaceutical care services to their customers with chronic diseases such as diabetes mellitus (91.5\%), hypertension (90.6\%), hyperlipidaemia (83.0\%), asthma (72.3\%) and others (10.7\%) which included skin problems, hyperuricaemia and gastrointestinal problems. Most of these respondents reported that they provided pharmaceutical care services to less than 20 patients in the recent one month.

\section{Factors associated with the provision of pharmaceutical care}

Similar factors were analysed using binary logistic regression mentioned. Only demographic factors that were significantly associated with the provision of pharmaceutical care services are shown in Table 3. 
Table 3

Factors associated with the provision of the pharmaceutical care services $(\mathrm{N}=409)^{\mathrm{a}}$

\begin{tabular}{|c|c|c|c|c|c|c|c|}
\hline \multirow[t]{2}{*}{ Provision } & \multirow[t]{2}{*}{ Factors } & \multirow[t]{2}{*}{ Characteristics } & \multirow[t]{2}{*}{$\begin{array}{l}\text { Frequency } \\
(\%)\end{array}$} & \multirow[t]{2}{*}{$\begin{array}{l}\text { Odds Ratio }(95 \% \\
\text { Cl) }\end{array}$} & \multirow{2}{*}{$\begin{array}{l}\text { Adjusted } \\
\text { p-value }\end{array}$} & \multicolumn{2}{|c|}{$\begin{array}{l}\text { Hosmer-Lemeshow Goodness of Fit } \\
\text { Test }\end{array}$} \\
\hline & & & & & & Chi-square & p-value \\
\hline \multirow{7}{*}{$\begin{array}{l}\text { Pharmaceutical care } \\
\text { service }\end{array}$} & \multirow[t]{3}{*}{ Ethnic } & Malay & $32(38.1)$ & As reference & - & \multirow[t]{7}{*}{3.104} & \multirow[t]{7}{*}{0.684} \\
\hline & & Chinese & $176(57.0)$ & $\begin{array}{l}2.210(1.320 \\
3.698)\end{array}$ & $0.003^{* *}$ & & \\
\hline & & Indian & $11(68.8)$ & $\begin{array}{l}3.988(1.248 \\
12.742)\end{array}$ & $0.020^{\star}$ & & \\
\hline & \multirow[t]{2}{*}{$\operatorname{cscsP}$} & Yes & $88(61.1)$ & $\begin{array}{l}1.594(1.032 \\
2.464)\end{array}$ & \multirow[t]{2}{*}{$0.036^{*}$} & & \\
\hline & & No & $131(49.4)$ & As reference & & & \\
\hline & \multirow[t]{2}{*}{$\begin{array}{l}\text { Methadone } \\
\text { HRP }\end{array}$} & Yes & $18(81.8)$ & $\begin{array}{l}3.751(1.129 \\
12.461)\end{array}$ & \multirow[t]{2}{*}{$0.031^{*}$} & & \\
\hline & & No & $201(51.9)$ & As reference & & & \\
\hline \multicolumn{8}{|c|}{ a Eleven respondents from other ethnic groups were excluded from analysis due to insufficient number for statistical comparison } \\
\hline \multicolumn{8}{|l|}{$* p<0.05 ; * \star p<0.01$} \\
\hline \multicolumn{8}{|c|}{ CSCSP - Certified smoking cessation service provider } \\
\hline HRP - Harm reduction & & & & & & & \\
\hline
\end{tabular}

Table 4 summarises the practice of all the five principles of pharmaceutical care by the respondents. Among the 420 respondents, only $0.95 \%$ (4) provided all the components in all the five practice principles of pharmaceutical care by APhA.

Table 4

Summary of respondents who fulfilled the practice principles of pharmaceutical care $(\mathrm{N}=420)$

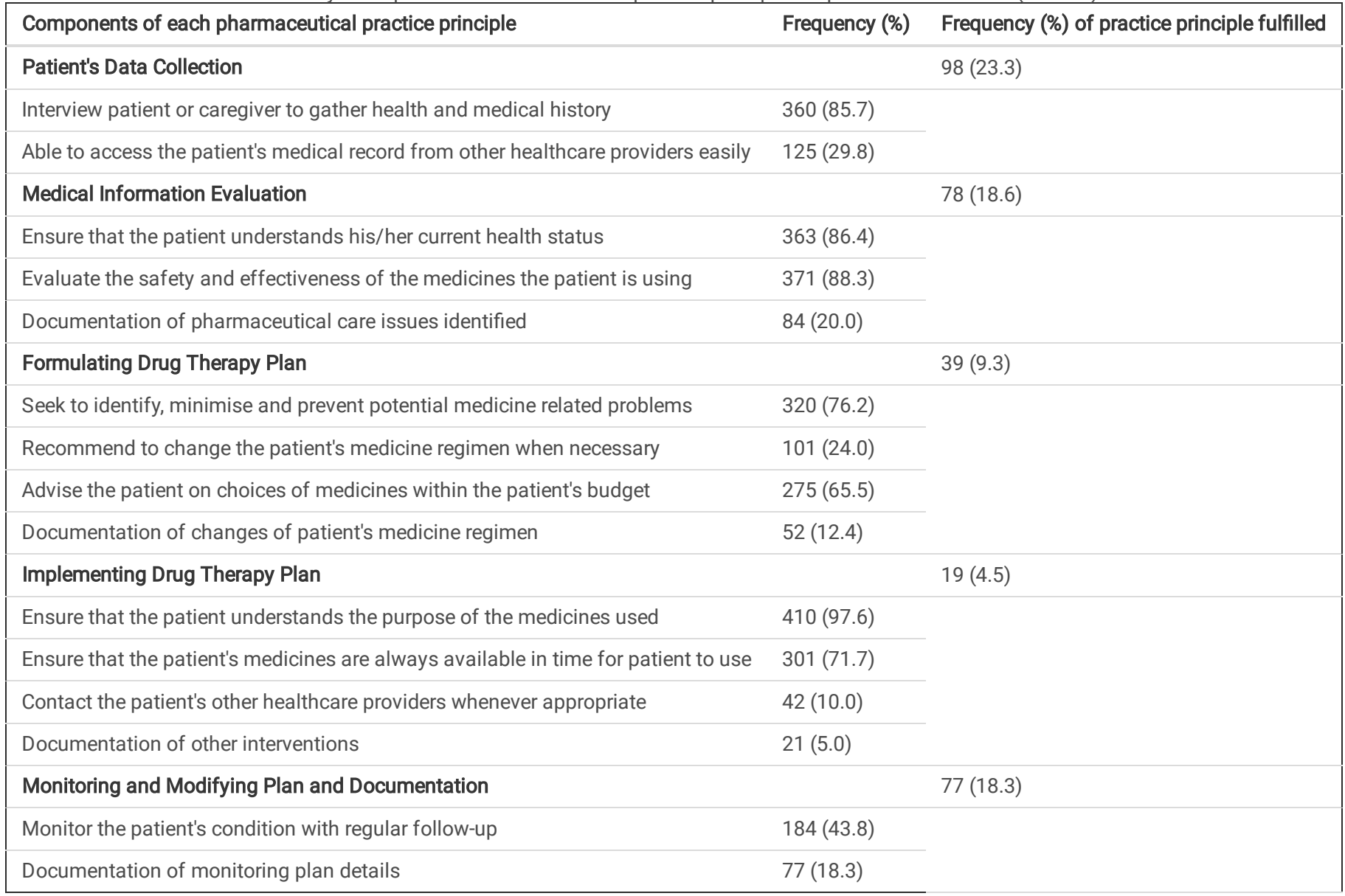


Table 5 shows the factors associated with the practice of components in the five practice principles of pharmaceutical care.

Table 5

Factors associated with the components in the five practice principles of pharmaceutical care $(\mathrm{N}=409)$ a.

\begin{tabular}{|c|c|c|c|c|c|c|c|}
\hline \multirow[t]{2}{*}{ Practices } & \multirow[t]{2}{*}{ Factors } & \multirow[t]{2}{*}{ Characteristics } & \multirow[t]{2}{*}{$\begin{array}{l}\text { Frequency } \\
(\%)\end{array}$} & \multirow[t]{2}{*}{$\begin{array}{l}\text { Odds Ratio } \\
(95 \% \mathrm{Cl})\end{array}$} & \multirow[t]{2}{*}{$p$-value } & \multicolumn{2}{|c|}{$\begin{array}{l}\text { Hosmer-Lemeshow } \\
\text { Goodness of Fit test }\end{array}$} \\
\hline & & & & & & Chi-square & p-value \\
\hline \multirow[t]{2}{*}{ Interview patient or caretaker } & \multirow[t]{2}{*}{ DMTAC } & Yes & $18(75.0)$ & As reference & \multirow[t]{2}{*}{$0.044^{\star}$} & \multirow[t]{2}{*}{3.781} & \multirow[t]{2}{*}{0.706} \\
\hline & & No & $334(86.8)$ & $\begin{array}{l}3.192(1.033 \\
9.863)\end{array}$ & & & \\
\hline \multirow{2}{*}{$\begin{array}{l}\text { Can access information from patient's other } \\
\text { health care providers }\end{array}$} & \multirow[t]{2}{*}{ Ethnic } & Malay & $17(20.2)$ & As reference & \multirow[t]{2}{*}{$0.026^{*}$} & \multirow[t]{2}{*}{4.405} & \multirow[t]{2}{*}{0.732} \\
\hline & & Chinese & $102(33.0)$ & $\begin{array}{l}1.958(1.085 \\
3.531)\end{array}$ & & & \\
\hline \multirow{2}{*}{$\begin{array}{l}\text { Seek to identify, minimise and prevent medical } \\
\text { related problems }\end{array}$} & \multirow[t]{2}{*}{ Ethnic } & Malay & $54(64.3)$ & As reference & \multirow[t]{2}{*}{$0.002^{\star \star}$} & \multirow[t]{2}{*}{1.735} & \multirow[t]{2}{*}{0.884} \\
\hline & & Chinese & $250(80.9)$ & $\begin{array}{l}2.370(1.371 \\
4.096)\end{array}$ & & & \\
\hline \multirow{5}{*}{$\begin{array}{l}\text { Recommend changes of medicine when } \\
\text { necessary }\end{array}$} & \multirow[t]{3}{*}{ Ethnic } & Malay & 10 (11.9) & As reference & - & \multirow[t]{5}{*}{4.568} & \multirow[t]{5}{*}{0.803} \\
\hline & & Chinese & $83(26.9)$ & $\begin{array}{l}2.721(1.292 \\
5.732)\end{array}$ & $0.008^{\star \star}$ & & \\
\hline & & Indian & $5(31.3)$ & $\begin{array}{l}4.253(1.176 \\
15.389)\end{array}$ & $0.027 *$ & & \\
\hline & \multirow[t]{2}{*}{ Employment } & Self-employed & $58(32.2)$ & $\begin{array}{l}2.138(1.312 \\
3.483)\end{array}$ & \multirow[t]{2}{*}{$0.002^{\star \star}$} & & \\
\hline & & $\begin{array}{l}\text { Full-time } \\
\text { employee }\end{array}$ & $40(17.5)$ & As reference & & & \\
\hline \multirow[t]{2}{*}{ Advise patient on medicines budget } & \multirow[t]{2}{*}{ Ethnic } & Malay & $44(52.4)$ & As reference & \multirow[t]{2}{*}{$0.004^{\star \star}$} & \multirow[t]{2}{*}{5.999} & \multirow[t]{2}{*}{0.306} \\
\hline & & Chinese & $217(70.2)$ & $\begin{array}{l}2.109(1.274 \\
3.491)\end{array}$ & & & \\
\hline Monitor patient's condition with regular follow up & Age & Below 40 & $112(49.6)$ & $\begin{array}{l}1.670(1.097 \\
2.542)\end{array}$ & $0.017^{*}$ & 3.759 & 0.807 \\
\hline & & 40 and above & $67(36.6)$ & As reference & & & \\
\hline & Ethnic & Malay & $27(32.1)$ & As reference & $0.032^{*}$ & & \\
\hline & & Chinese & $145(46.9)$ & $\begin{array}{l}1.774(1.050 \\
2.995)\end{array}$ & & & \\
\hline Contact patient's other health care providers & Employment & Self-employed & $25(13.9)$ & $\begin{array}{l}2.305(1.152, \\
4.613)\end{array}$ & $0.018^{*}$ & 2.234 & 0.897 \\
\hline & & $\begin{array}{l}\text { Full-time } \\
\text { employee }\end{array}$ & $15(6.6)$ & As reference & & & \\
\hline Eleven respondents from other ethnic groups wer & excluded from & alysis due to ins & ficient num & r for statistic & mparisor & & \\
\hline$\star p<0.05 ; * \star p<0.01$ & & & & & & & \\
\hline DMTAC - Diabetes medicine therapy adherence clir & & & & & & & \\
\hline
\end{tabular}

\section{Barriers in providing pharmaceutical care services}

Table 6 shows the perceived barriers by the respondents in implementing pharmaceutical care services at their community pharmacies. 
Areas and statements of barrier
Mean

Score (SD)
Number of respondents (\%) $[\mathrm{N}=420]$

Strongly Disagree Slightly Disagree and Disagree and Slightly Agree
Agree and Strongly Agree

Time

Lack of time from your side.

Patient or customer has no time.

\section{Space or privacy}

Lack of space in the pharmacy premises for the patient's privacy.

\section{Finances}

Lack of financial incentive.

Increased operating cost.

\section{Resources}

Shortage of manpower to provide the service

Lack of training to provide the service

pharmacy software

Lack of hard copy references such as BNF, MIMS etc.
3.15

(1.32)

3.50

(1.11)
67 (15.9)

$38(9.0)$

(9.0)

143 (34.0)

2.48
$(1.46)$
146 (34.8)

115 (27.4)

149 (35.5)

$127(30.2)$

147 (35.0)

98 (23.3)

2.91
$(1.41)$

2.98
$(1.46)$
2.91
$(1.41)$

99 (23.6)

.

121 (28.8)

$265(63.1)$

(1.16)

3.04

(1.35)

2.48

(1.44)

1.81

(1.29)

\section{Public awareness}

Lack of public awareness that such service is available at your community pharmacy

46 (11.0)

$144(34.3)$

$230(54.7)$

\section{Supports from other health care providers}

Restriction by pharmaceutical suppliers on access of certain medicines to your pharmacy

3.19
$(1.26)$

Medicine price discrimination by pharmaceutical suppliers.

3.99

(1.09)

Lack of acceptance by doctors on recommendation of medicine regimens by

the pharmacist

3.72

(1.05)

78 (18.6)

145 (34.5)

197 (46.9)

$138(32.9)$

159 (37.9)

$123(29.2)$

$222(52.9)$

$140(33.3)$

$58(13.8)$

$267(63.6)$

$128(30.5)$

$194(46.2)$

175 (41.7)

\section{Government or professional health care Policy}

Lack of dispensing separation which reduces the opportunity for patients who need pharmaceutical care to visit your pharmacy

Lack of government's initiative for patients to obtain their prescribed medicines from your pharmacy

Strict enforcement which prevents the supply of follow-up prescription medicines without a valid or complete prescription from doctors

4.00

No standard guidelines by the government or professional bodies on pharmaceutical care services

$163(38.8)$

$81(19.3)$

$136(32.4)$

$17(4.0)$

$14(3.4)$

$13(3.1)$

$20(4.8)$

$23(5.5)$

(2)

aAmong 420 respondents, only 233 were employed pharmacists

BNF - British National Formulary; MIMS - Monthly Index of Medical Specialities 


\begin{tabular}{|c|c|c|c|c|}
\hline \multirow[t]{2}{*}{ Areas and statements of barrier } & \multirow{2}{*}{$\begin{array}{l}\text { Mean } \\
\text { Score } \\
\text { (SD) }\end{array}$} & \multicolumn{3}{|c|}{ Number of respondents (\%) [N= 420] } \\
\hline & & $\begin{array}{l}\text { Strongly Disagree } \\
\text { and Disagree }\end{array}$ & $\begin{array}{l}\text { Slightly Disagree } \\
\text { and Slightly Agree }\end{array}$ & $\begin{array}{l}\text { Agree and } \\
\text { Strongly } \\
\text { Agree }\end{array}$ \\
\hline \multicolumn{5}{|l|}{ Support from employer $(\mathrm{N}=233)^{a}$} \\
\hline Lack of support from your employer & $\begin{array}{l}2.10 \\
(1.40)\end{array}$ & $100(42.9)$ & $84(36.1)$ & $49(21.0)$ \\
\hline \multicolumn{5}{|c|}{ aAmong 420 respondents, only 233 were employed pharmacists } \\
\hline BNF - British National Formulary; MIN & & & & \\
\hline
\end{tabular}

Of the 18 statement on barriers, the lack of separation between prescribing and dispensing had the highest mean score (SD) of 4.20 (1.01) as well as the highest percentage of 'agree and strongly agree' response (84.0\%). This indicates that community pharmacists perceived this as the greatest barrier for providing pharmaceutical care.

\section{Discussion}

The present study found that almost all the respondents (99.5\%) were providing some types of health screening and monitoring, mainly the measurement of blood pressure, blood glucose and cholesterol levels. This is higher than from a previous nationwide study (77.1\%) by Chua et al [16]. This may be attributed to an increase in awareness and demand by the general public [31] especially by those who could not afford home-used medical devices [32]. Nevertheless, future studies should also examine the quality and effectiveness of such services in detecting and monitoring the prevalence of non-communicable diseases in the country. This is especially important as the Ministry of Health Malaysia is considering a public-private partnership [24] in which community pharmacists can play an important role in the screening of non-communicable diseases among lower-income population, as well as providing continuous health monitoring if the Transition of Care programme where patients can be referred to the community pharmacies to reduce the overload in the public health care system, is implemented.

Most of the respondents (90.5\%) also advised their customers on the selection and use of health supplements for general health. This is in agreement with a study by Chua et al. [13] which reported that the general public in Malaysia approached community pharmacists mainly to purchase health supplements. However, only $15.8 \%$ of the respondents who provided such services were accredited with CMEd. In addition, the odds of providing such service among the community pharmacists with a basic pharmacy degree is almost 5.0 times more than those with a master's degree. This raises the question of whether CMEd or a master's degree is essential for providing such services. Further studies are required to assess whether those without such qualifications are also able to provide effective counselling on health supplements. In addition, pharmacy programmes in Malaysia should include topics on health supplements in their curriculum to better equip future pharmacists.

More than two-thirds of the respondents were conducting patient medications reviews in the pharmacies and this was 10 times higher than those who were conducting home medication reviews. This may be due to a shortage of pharmacists or staff as shown in the present study where more than half of the respondents $(63.1 \%)$ cited the shortage of manpower and hence, community pharmacists were not able to leave their pharmacies to conduct home medication reviews. Another reason could be a lack of clinical knowledge and skills in providing home medication review as the present study found that the odds of providing such service among community pharmacists with a master's degree were 3.7 times more than those with a basic degree. Further studies on the processes of medication review in the pharmacies or in the homes of patients by community pharmacists are also required to determine if these were carried out comprehensively or consistently as in Australia [33] or other countries [8,34] which have incorporated the practice principles for pharmaceutical care in their medication review.

About half of the respondents (51.0\%) were providing counselling on smoking cessation to assist the general public to quit smoking. This is similar to the findings by Chua et al. (49.1\%) [16]. The war against smoking will continue and the demand for advice to quit smoking may increase in future. In addition, the present study showed that only slightly more than half (53.7\%) of those who were providing counselling on smoking cessation have undergone the CSCSP programme while the odds of providing smoking cessation service among those with CSCSPs was 8.2 times more than those without such certification. This shows that community pharmacists should be encouraged to attend the CSCSP programme to ensure that they are appropriately trained to provide such services. Further studies should also be conducted to determine the effectiveness of such service provided by community pharmacists.

Despite health care demand on weight management due to its association with an increased risk of non-communicable diseases and the national health care expenditure, the present study showed that only slightly more than half of the respondents (52.4\%) were providing weight management service. In addition, the odds of such practice were almost 1.8 times higher among pharmacists aged below 40 years compared to those 40 years old and above. Such service is not widely available among community pharmacies probably because the general public in Malaysia preferred to seek advice from dietitians and fitness instructors than from community pharmacists for weight management services, as most people are not aware of such service by community pharmacists [35].

Waste management in community pharmacies involved the collection of expired, damaged, or unused medicines and used needles from customers, for proper disposal. In 2018, a pilot project was initiated in Malaysia by the Malaysian Community Pharmacy Guild to empower community pharmacists to educate and assist the general public on the proper disposal of used needles. This was followed by the Green Pharmacy campaign which expanded its services to community pharmacies nationwide and includes other forms of clinical waste [36]. Despite the initiative taken through several campaigns, the present study

Page 10/16 
found that only a small percentage (7.9\%) of community pharmacies were providing waste management service. This is as expected since such service is still relatively new and may need some incentives for the community pharmacies as well as more public awareness campaigns.

Multiple medicine management involves the use of medicine dose administration aid that can be provided by community pharmacists. This is beneficial to patients who have complex or multiple medicine regimens and especially for elderly patients to improve their medication adherence [37]. With the growing ageing population (aged 60 and older) in Malaysia, from 7.7\% in 2010 to the estimated 14.7\% in 2030 [38], community pharmacists can play a major role in assisting geriatric patients to manage their medications since they are most susceptible to polypharmacy. However, the present study showed that not many respondents were offering such service. Thus, community pharmacists should expand their services to geriatric nursing homes to optimise medication use and minimise medication errors [37].

Slightly more than half of the respondents (53.3\%) reported that they were providing pharmaceutical care services in their community pharmacies, mainly for patients with diabetes, hypertension, hyperlipidaemia and asthma. However, whether these community pharmacists were familiar with the concept and were practising appropriate pharmaceutical care processes were not captured in this study. A study of community pharmacists in Brazil reported that those who were providing pharmaceutical care did not have adequate knowledge of this service and even lesser knowledge than those who did not provide such service [39].

The present study on pharmaceutical care practices found that more than two-thirds of the respondents reported that they were not able to access patients' medical information from the patients' medical doctors. Besides a lack of co-operation from the patients' medical doctors, there was a lack of acceptance by patients to allow community pharmacists to access their medical conditions and to provide pharmaceutical care. These findings are similar to that of studies in many other developing countries where the general public's awareness on the roles of community pharmacists' is still very limited [40,41].

The study also revealed that some of the respondents (14.3\%) did not gather medical information from their patients or their caregivers before providing their recommendations. Community pharmacists should be more vigilant in responding to patients' request for treatment as insufficient patients' medical information may lead to inappropriate treatment recommendation and subsequently, may lead to more harm than good to the patients.

Even though more than $80 \%$ of the respondents in the present study claimed that they evaluated the safety and effectiveness of the medicines the patients were taking and ensured that their patients understood their current health conditions, most did not document such evaluation and its outcomes. Community pharmacists should be more conscientious to carry out comprehensive documentation which is essential for the effective practice of pharmaceutical care where pharmacists should monitor the drug therapy plan, detect any undesirable outcomes and if required, to modify the therapy plan [1].

Most of the respondents (76.2\%) reported that they identified, minimised and prevented potential medicine-related problems while formulating a drug therapy plan. Studies in China (93.1\%) and Nigeria (91.1\%) also showed that a majority of the pharmacists identified medicine-related problems when devising pharmaceutical care plans $[41,42]$.

The present study found that only about $25 \%$ of the respondents would recommend changes to the patient's medication regimen when required, compared to $55 \%$ of community pharmacists in Nigeria [42]. Documentation of a change in medicine was also rarely done. This may be because community pharmacists in Malaysia do not receive many prescriptions with multiple medications since such prescriptions are usually filled in the hospitals or the clinics of general practitioners. Therefore, community pharmacists are not actively involved in the management of patients' medication regimens and in intervening medicationrelated problems. Similar situations were also observed in Indonesia [43].

Only $10 \%$ (42) of the respondents would contact their patients' medical doctors to discuss the need to change the patients' medication regimens when appropriate and only half of these respondents documented their interventions. These findings are similar to that of a study in India where a majority of the community pharmacists did not contact the patients' medical doctors on prescription issues [44]. A previous study in Malaysia also found that almost all (98.9\%) the medical doctors in private clinics never had any interactions with community pharmacists [45]. Factors that may have prevented community pharmacists from contacting the prescribers included poor relationship between the two health care professionals [41], and a lack of awareness or acceptance of pharmacists' roles by the prescribers [45-47].

Proper monitoring could be the most important component of pharmaceutical care to detect any undesirable outcomes, but this is usually the least practised [1]. The present study found that less than $20 \%$ (77) of the respondents were monitoring and modifying the drug therapy plans for their patients. This finding is similar to studies in Jordan [46] and Saudi Arabia [48].

Community pharmacists in Malaysia rarely document their pharmaceutical care services including the outcomes of their interventions. Poor documentation was also observed in studies on community pharmacist services in Jordan [46] and Brazil [39]. The reason for not documenting the drug therapy plan for monitoring purpose could be the absence of regulations to keep patients' medical records, and also most community pharmacists thought that it is not necessary or are too busy to maintain any document [49]. Documentation of pharmaceutical services provided should be done for the proper practice of monitoring and modifying of a drug therapy plan.

Ethnicity, employment status and age seemed to determine whether the community pharmacists would conduct the various steps in the practice of pharmaceutical care. Self-employed community pharmacists were more proactive in contacting the patient's other health care providers and recommending changes to the medications. This is as expected since most self-employed individuals will be more enthusiastic and will spend more time talking to their customers [19]. More in-depth studies such as qualitative studies will be useful to determine how ethnicity affects the provision of pharmaceutical care services. 
The present study found that community pharmacists in Malaysia were not providing adequate pharmaceutical care services in the following areas: collaborating with patients' other health care providers to obtain their medical and medication information; managing the patient's medication regimen including the recommendation to change medication when required; having proper patient monitoring and follow-up mechanism, and; maintaining documentation of pharmaceutical care services.

The most common barriers that prevented community pharmacists from providing pharmaceutical care services in the present study were government or professional health care policies such as the absence of separation between prescribing and dispensing; government initiative for patients to obtain their prescribed medications from community pharmacies; strict enforcement on the dispensing of prescription-only-medicines with valid prescriptions and lack of standard guidelines on pharmaceutical care services. Lack of supportive health care policies had also been cited as one of the main barriers in other studies [41, 46] including in Malaysia [14] and even in South Korea which practices separation between prescribing and dispensing [29]. The small number of prescriptions received by the community pharmacies in the present study did not provide much opportunity for community pharmacists to provide pharmaceutical care services as patients with chronic and multiple medications seldom visit these pharmacies to fill their prescriptions. The implementation of separation between prescribing and dispensing is a major health care reform which may require political will, time and resources. Perhaps, the authorities concerned can emulate the community pharmacy practice in Thailand where incentives are given to community pharmacists to provide the following services: prescription refill, health screening for patients with chronic disease, smoking cessation counselling and Medicine Management Therapy [50].

Another barrier reported was medicine price discrimination by pharmaceutical suppliers. Some medications were not available or were sold to community pharmacies at higher prices $[51,52]$ and hence, costs of prescribed medications may be higher compared to private hospitals or clinics. This may prevent patients from filling their prescriptions in community pharmacies and consequently less opportunity for prescription screening and for identifying any medication-related problems as well as to provide pharmaceutical care services.

Lack of acceptance by medical doctors for community pharmacists to provide pharmaceutical care services was commonly cited by studies in many developing countries $[42,43,47]$. The present study also found that many respondents $(63.6 \%)$ reported a lack of acceptance by doctors on recommendation of medication regimens by the pharmacist. This could be due a lack of doctors' understanding regarding the clinical knowledge of pharmacists. However, an Indonesia study showed that doctors who had worked closely with community pharmacists expressed their trusts on these healthcare professionals [47]. This indicates the importance of open discussion to foster closer collaboration between both health care professionals in providing optimal care to the patients.

Other barrier statements stated by more than $50 \%$ of the respondents were: patient or customer had no time; shortage of manpower at the pharmacies; and lack of public awareness. These factors could be inter-related because if the general public is adequately informed about the roles of pharmacists, they will be more willing to trade their time for the benefits of pharmaceutical care. Subsequently, with increased demand from customers, the pharmacies will also increase their manpower. Creating public awareness of pharmaceutical care services provided by community pharmacies will increase the utilization of such service and hence, community pharmacists can also contribute to the healthcare system of the country.

\section{Limitations Of The Study}

The first limitation of this study was that the contact list of community pharmacists may not be complete. Therefore, some community pharmacists might have been missed out and did not have the opportunity to participate in the online self-administered questionnaire.

Secondly, as this is the first study on pharmaceutical care services provided by community pharmacists in Malaysia based on the five practice principles for pharmaceutical care stipulated by the APhA [2], the components used to verify each principle may not be foolproof. Nevertheless, this did not affect the findings of the present study where the practice of all these principles by community pharmacists in Malaysia were sub-optimal. More importantly, this study showed the areas of pharmaceutical care services that need improvement by community pharmacists. Future studies should also assess the extent or depth of pharmacy programme curricula in Malaysia which cover such services so that appropriate interventions can be planned and implemented.

\section{Conclusions}

Most community pharmacies in Malaysia were involved in recommending health supplements, conducting patient medication reviews, weight management and smoking cessation services. However, the concerns were whether such services had been adequately delivered since not all community pharmacists were accredited or certified in these skills. Future studies on the quality and effectiveness of these services should be considered.

The present study found that community pharmacists in Malaysia were not providing adequate pharmaceutical care services in comparison to international practice principles. The current government or professional health care policies were reported as the main barrier in providing pharmaceutical care services. Authorities concerned should take this into consideration when planning the health care system.

\section{Abbreviations}

APhA: American Pharmacists Association; MPS: Malaysian Pharmaceutical Society; SD: Standard deviation; IQR: Interquartile range; CMEd: Complementary medicine education; CSCSP: Certified smoking cessation service provider; HRP: Harm reduction program; DMTAC: Diabetes medicine therapy adherence clinic; Cl: Confidence interval; BNF: British national formulary; MIMS: Monthly index of medical specialities; n.d.: no date.

\section{Declarations}

Ethics approval

Page $12 / 16$ 
The study was conducted using an online survey. If the invited pharmacists agreed to participate in the study, they were required to click a checkbox for consent before they could proceed to do the questionnaire.

The study had been reviewed and approved by the Human Ethics Committee of Taylor's University Malaysia (reference number: HEC 2018/002).

\section{Consent for publication}

Not applicable.

\section{Availability of data and materials}

The datasets used and/or analysed for the present study are available from the corresponding author upon reasonable request.

\section{Competing interests}

The authors declare that they have no competing interests.

\section{Funding}

The authors did not receive any funding or financial support for this research work.

\section{Authors' contributions}

PL and SSC contributed in the design of the study. PL was responsible for the preparation, data collection and analysis of the study, and also prepared the first draft of the manuscript and edited it. SSC was involved in the data analysis and interpretation as well as editing of the manuscript while MK was involved in checking and interpretation of the results as well as editing the manuscript. All authors read and approved the final manuscript.

\section{Acknowledgements}

We wish to thank Dr Sharmini Balashankar and Dr Adam Turner from Faculty of Science, Nottingham University of Malaysia Campus for their guidance during the early stage of the research. A very special thanks to Ms Rhia Desai, a pharmacy student at University of Nottingham, United Kingdom, for her assistance in setting up the survey questionnaire using the Survey Monkey ${ }^{\circledR}$. We are also very grateful to the community pharmacists who were involved in validating the questionnaires for this study: Azhar bin Najuddin, Azlie bin Md Yaakub, Bharati a/p Suresh Chand, Che Rahim bin Che Daud, Fauzan bin Mohamed Dzahir, Francis Tan Peng Nam, Goh Chun Kok, Jerry Tan Sze Eng, Lai Jian Chen, Lee Yin Chen, Lim Kean Ping, Merinda Chua Li Chuen, Mohamad Azree bin Jawawi, Naszri bin Abu Samah, Ngu Soon Hieng, Nik Jah bt Nik Ab Kadir, Pang Wee Siang, Ruhani bt Ismail, Salina bt Abdul Wahid, Sally Chuah Sze Yee, Santhanathan a/I S. Rajendram, Siah Kim Meng, Wang Leong Seng, Wan Mohd Hamidi bin Wan Sulaiman, Wong Sie Sing, and Yip Sook Ying.

\section{References}

1. Hepler, C. D., \& Strand, L. M. (1990). Opportunities and responsibilities in pharmaceutical care. American Journal of Hospital Pharmacy, 47(3), 533-43. PMID: 2316538

2. American Pharmacists Association (APhA). (1995). Principles of practice for pharmaceutical care. Retrieved June 2, 2018, from http://www.pharmacist.com/principles-practice-pharmaceutical-care

3. Fikri-Benbrahim, N., José Faus, M., Martí nez-Martí nez, F., \& Sabater-Herna' ndez, D. (2013). Impact of a community pharmacists' hypertension-care service on medication adherence. The AFenPA study. Research in Social and Administrative Pharmacy, 9, 797-805. doi: https://doi.org/10.1016/j.sapharm.2012.12.006

4. Stuurman-Bieze, A. G. G., Hiddink, E. G., van Boven, J. F. M., \& Vegter. S. (2013). Proactive pharmaceutical care interventions improve patients' adherence to lipid- lowering medication. The Annals of Pharmacotherapy, 47(11), 1448-1456. doi: https://doi.org/10.1177/1060028013501146

5. Stuurman-Bieze, A. G. G., Hiddink, E. G., van Boven, J. F. M., \& Vegter. S. (2014). Proactive pharmaceutical care interventions decrease patients' nonadherence to osteoporosis medication. Osteoporosis International, 25, 1807-1812. doi: https://doi.org/10.1007/s00198-014-2659-8

6. Chung, W. W., Chua, S. S., Lai, P. S. M., Chan, S. P. (2014). Effects of pharmaceutical care model on medication adherence and glycemic control of people of type 2 diabetes. Patient Preference and Adherence, 8, 1185-1194. doi: https://doi.org/10.2147/PPA.S66619

7. Lee, Y. L., Rosnani, H., Syed, A. S. S, Syed, W. G., Yelly, O. S., \& Usman, H. (2011). Impact of a community pharmacist-based diabetes management program on clinical outcomes measures. International Research Journal of Pharmacy and Pharmacology 1(3), 033-042. Retrieved November 9, 2018, from https://www.interesjournals.org/articles/impact-of-a-community-pharmacistbased-diabetes-management-program-on-clinical-outcomes-measures.pdf

8. Pinto, S. L., Kumar, J., Partha, G., \& Bechtol, R. A. (2013). Pharmacist-provided medication therapy management (MTM) program impacts outcomes for employees with diabetes. Population Health Management. doi: https://doi.org/10.1089/pop.2012.0124

9. Thavornwattanayong, W. \& Sribundit, N. (2016). Effects of family pharmacy intervention on clinical outcomes in primary care settings in Thailand. Thai Journal of Pharmaceutical Sciences, 41 (1): 35-40. Retrieved September 14, 2019, from http://www.thaiscience.info/Journals/Article/TJPS/10984266.pdf

10. Cheen, M. H. H., Goon, C. P., Ong, W. C., Lim, P. S., Wan, C. N., Leong M. Y., \& Khee, G. Y. (2016). Evaluation of a care transition program with pharmacistprovided home-based medication review for elderly Singaporeans at high risk of readmissions. International Journal for Quality in Health Care, 2017, 29(2), 200-205. doi: https://doi.org/10.1093/intqhc/mzw150 
11. Luder, H. R., Frede, S. M., Kirby, J. A., Epplen, K., Cavanaugh, T., Martin-Boone, J. E., Conrad, W. F., Kuhlmann, D., \& Heaton, P. C. (2015). TransitionRx: Impact of community pharmacy postdischarge medication therapy management on hospital readmission rate. Journal American Pharmacists Association, 55, 246-254. doi: https://doi.org/10.1331/JAPhA.2015.14060

12. Tommelein, E., Mehuys, E., Van Hees, T., Adriaens, E., Van Bortel, L., Christiaens, T., Van Tongelen, I., Remon, J., Bousser, K., \& Brusselle. G. (2013). Effectiveness of pharmaceutical care for patients with chronic obstructive pulmonary disease (PHARMACOP): A randomized controlled trial. British Journal of Clinical Pharmacology, 77(5), 756-766. doi: https://doi.org/10.1111/bcp.12242

13. Chua, S. S., Lim, K. P., \& Lee, H. G. (2013). Utilisation of community pharmacists by the general public in Malaysia. International Journal of Pharmacy Practice, 21, 61-69. doi: https://doi.org/10.1111/j.2042-7174.2012.00219.x

14. Hassali, M. A., Li, V. M. S., \& See, O.G. (2014). Pharmacy practice in Malaysia. Journal of Pharmacy Practice and Research, 44, 125-128. doi: https://doi.org/10.1002/jppr.1024

15. Loo, J. S. E., Loh, M. H., Tiong, J. J. L. (2018). An evaluation of prescriptions dispensed in Malaysian community pharmacies in the absence of dispensing separation. Indian Journal of Pharmaceutical Sciences, 80(2), 390-395. doi: https://doi.org/10.4172/pharmaceutical-sciences.1000370

16. Chua, S. S., Wong, W. K., Lee, H. G., Richard, Y., \& Tan, J. S. H. (2008). Implementation of the benchmarking guidelines on community pharmacies in Malaysia. Malaysian Journal of Pharmaceutical Sciences, 6(1), 13-31. Retrieved December 14, 2017, from http://web.usm.my/mjps/mjps06012008/mjps06012008_2.pdf

17. Beshir, S.A. \& Hamzah, N. H. (2014). Health promotion and health education: Perception, barriers and standard of practices of community pharmacists. International Journal of Health Promotion and Education, 52(4), 174-180. doi: https://doi.org/10.1080/14635240.2014.888809

18. Sam, A. T., Jothy, T. H., \& Parasuraman, S. (2015). Assessment of pharmaceutical care services provided by a community pharmacy in Kedah, Malaysia. Pharmacology, Toxicology and Biology (PTB)Report, 1(2), 73-80. doi: https://doi.org/10.5530/ptb.1.2.7

19. Chua, S.S., Ramachandran, C.D., \& Paraidathathu, T.T. (2006). Response of community pharmacists to the presentation of back pain: a simulated patient study. International Journal of Pharmaceutical Practice, 14, 171-178. doi: https:/doi.org/10.1211/ijpp.14.3.0003

20. Khan, T. M., Emeka, P., \& Khan, A. H. (2013). Drug Information Activity and Nonprescription Requests Over the Malaysian Counter. Therapeutic Innovation \& Regulatory Science, 47(2), 198-202. doi: https://doi.org/10.1177/2168479012462214

21. Cavaco, A. (2018). Pharmaceutical care and patient counseling. The Pharmacist Guide to Implementing Pharmaceutical Care. In: da Costa, van Mil, J. W. F., \& Alvarez-Risco, A. eds. (pp. 33-40). Springer, Cham. doi: https://doi.org/10.1007/978-3-319-92576-9_4

22. International Pharmaceutical Federation (FIP). (2012). Counselling, concordance and communication: innovative education for pharmacists. 2nd edn. EdFIP/IPSF.11-12. Retrieved April 5, 2019, from https://fip.org/files/fip/HaMIS/fip_ipsf_pce_2nd_2012.pdf.

23. Pharmaceutical Service Division (PSD), Ministry of Health Malaysia. (2017, October 11). Statistik farmasi 2016. Retrieved March 12, 2018, from: https://www.pharmacy.gov.my/v2/sites/default/files/statistic/Statistik\%20Farmasi\%202016_0.pdf

24. Ahmad, D. (2019). Enhancing sustainability in healthcare delivery: A challenge to the New Malaysia. Malaysian Journal of Medical Sciences, 26(1), 1-4. doi: https://doi.org/10.21315/mjms2019.26.1.1

25. Pharmaceutical Service Division (PSD), Ministry of Health Malaysia. (2017, January 4). Community pharmacy benchmarking guideline 2016. Retrieved February 14, 2018, from https://www.pharmacy.gov.my/v2/en/documents/community-pharmacy-benchmarking-guideline.html

26. Hassali, M. A., Saleem, F., Khan, T.M., Aljadhey, H., Farooqui, M., \& Haq, N. U. (2013). Pharmacists' perception of the sale of non-clinically proven health supplements in Penang, Malaysia. Tropical Journal of Pharmaceutical Research, 12(3), 433-438. doi: https://doi.org/10.4314/tjpr.v12i3.23

27. Bursac, Z., Gauss, C. H., Williams, D. K., \& Hosmer, D. (2007). A purposeful selection of variables macro for logistic regression. Journal of Source Code for Biology and Medicine, 3, (173). Retrieved April 2, 2019, from https://support.sas.com/resources/papers/proceedings/proceedings/forum2007/1732007.pdf

28. (n.d.). Test of model fit. Retrieved April 29, 2020, from https://www.ibm.com/support/knowledgecenter/SSLVMB_24.0.0/spss/tutorials/log_loan_fit.html

29. Sohn, H. S., Kim, S. O., Joo, K. M., Park, H., Han, E., Ahn, H. T., \& Choi, S. E. (2015). Pharmacists' perceptions of barriers to providing appropriate pharmaceutical services in community pharmacies. Korean Journal of Clinical Pharmacy, 25(2), 94-101. ISSN: 1226-6051

30. Kelly, D. V., Bishop, L., Young, S., Hawboldt, J., Phillips, L., \& Keough, T. M. (2013). Pharmacist and physician views on collaborative practice: Findings from the community pharmaceutical care project. Canadian Pharmacists Journal, 146(4), 218-226. doi: https://doi.org/10.1177/1715163513492642

31. Bahari, M. B. \& Ling, Y. W. (2010). Factors contributing to customer satisfaction with community pharmacies in Malaysia. Journal of Public Health, 18, 35-41. doi: https://doi.org/10.1007/s10389-009-0280-7

32. Kho, B. P., Hassali, M. A., Lim, C. J., \& Saleem, F. (2017). A qualitative study exploring professional pharmacy services offered by community pharmacies in the state of Sarawak, Malaysia. Journal of Pharmaceutical Health Services Research, 8(3), 201-208. doi: https://doi.org/10.1111/jphs.12181

33. Chen, T. F., \& Nishtala, P. S. (2018). Pharmaceutical Care in Australia and New Zealand. The Pharmacist Guide to Implementing Pharmaceutical Care. In: da Costa, van Mil, J. W. F., \& Alvarez-Risco, A. eds. (pp. 173-182). Springer, Cham. doi: https://doi.org/10.1007/978-3-319-92576-9_15

34. Diaz Sierra, E. C. \& Melin, K. (2014). Clinical and behavioral impact of pharmaceutical care services in community pharmacies in Puerto Rico. Journal of Pharmaceutical Care and Health System, S1, 001. doi: https://doi.org/10.4172/jpchs.1000-S1-001

35. Verma R.K., Paraidathathu, T., Taha, N. A., \& Chong, W. W. (2018). Perceptions of the Malaysian general public on community pharmacy-based weight management services. Journal of Pharmaceutical Policy and Practice, 11, 17. doi: https://doi.org/10.1186/s40545-018-0146-x

36. Malaysian Community Pharmacy Guild (MCPG). (2019). Roadmap to advancing community pharmacy unveiled. Retrieved September 19, 2019, from http://mcpg.org.my/roadmap-to-advancing-community-pharmacy-unveiled/ 
37. Hersberger, K. E., Boeni, F., \& Arnet, I. (2013). Dose-dispensing service as an intervention to improve adherence to polymedication. Expert Review of Clinical Pharmacology, 6(4), 413-421. doi: https://doi.org/10.1586/17512433.2013.811829

38. World Health Organization Western Pacific Region (WPRO). (2014, March 25). Ageing and health: Malaysia. Retrieved December 13, 2017, from http://www.wpro.who.int/topics/ageing/ageing_fs_malaysia.pdf

39. Reis, T.M., Guidoni, C. M., Girotto, E., Rascado, R. R., Mastroianni, P. C., Cruciol, J. M., \& Pereira, L. R. L. (2015). Pharmaceutical care in Brazilian community pharmacies: Knowledge and practice. African Journal of Pharmacy and Pharmacology, 9(9), 287-294. doi: https://doi.org/10.5897/AJPP2014.4239

40. El-Dahiyat, F., Curley, L. E., \& Babar, Z. (2019). A survey study to measure the practice of patient counselling and other community pharmacy services in Jordan. Journal of Pharmaceutical Health Services Research, 10(1), 133-139. doi: https://doi.org/10.1111/jphs.12272

41. Fang, Y., Yang, S., Feng, B., Ni, Y., \& Zhang, K. (2011). Pharmacists' perception of pharmaceutical care in community pharmacy: a questionnaire survey in Northwest China. Health and Social Care in the Community, 19(2), 189-197. doi: https://doi.org/10.1111/j.1365-2524.2010.00959.x

42. Usman, M. H. \& llyas, O. S. (2014). Assessment of knowledge, attitude and practice of community pharmacists towards pharmaceutical care in Kaduna state, Nigeria. International Journal of Pharmacy Teaching \& Practices, 5(2), 972-976. Retrieved February 14, 2018 from,

https://www.researchgate.net/publication/264525651_Assessment_of_Knowledge_Attitude_and_Practice_of_Community_Pharmacist_towards_Pharmace

43. Puspitasari, H. P., Aslani, P., \& Krass, I. (2015). Challenges in the management of chronic noncommunicable diseases by Indonesian community pharmacists. Pharmacy Practice 2015 Jul-Sep;13(3):578. doi: https://doi.org/10.18549/PharmPract.2015.03.578

44. Deepalakshmi, M., Devipriya, T., Arun, K. P., \& Ponnusankar, S. (2016). Knowledge, attitude and practice of community pharmacists towards cognitive pharmaceutical care services in Tamil Nadu, India. Indian Journal of Pharmaceutical Science, 8(6), 844-849. doi: https://doi.org/10.4172/pharmaceuticalsciences.1000192

45. Sarriff, A., Nordin, N., \& Hassali, M. A. A. (2012). Extending the roles of community pharmacists: Views from general medical practitioners. Medical Journal of Malaysia, 67(6), 577-581. Retrieved December 16, 2017, from https://www.ncbi.nlm.nih.gov/pubmed/23770948

46. Elayeh, E., Akour, A., Almadaeen, S., AlQhewii T., \& Basheti I.A. (2017). Practice of pharmaceutical care in community pharmacies in Jordan. Tropical Journal of Pharmaceutical Research, 16 (2), 463-470. doi: https://doi.org/10.4314/tjpr.v16i2.27

47. Wibowo, Y., Sunderland, B., \& Hughes, J. (2016). Pharmacist and physician perspectives on diabetes service delivery within community pharmacies in Indonesia: A qualitative study. International Journal of Pharmacy Practice, 24, 180-188. doi: https://doi.org/10.1111/ijpp.12227

48. Ahmed, N. O. \& and Al-Wahibi, N. S. (2016). Knowledge, attitude and practice towards pharmaceutical care in community pharmacy in Saudi Arabia. British Journal of Medicine \& Medical Research, 15(9), 1-9. Article no. BJMMR.23920. doi: https://doi.org/10.9734/BJMMR/2016/23920

49. Elkalmi, R. M., Hassali, M. A., Ibrahim, M. I. M., Liau, S. Y., \& Awaisu, A. (2011). A qualitative study exploring barriers and facilitators for reporting of adverse drug reactions (ADRs) among community pharmacists in Malaysia. Journal of Pharmaceutical Health Services Research 2011 (2), 71-78. doi: https://doi.org/10.1111/j.1759-8893.2011.00037.x

50. Chaiyakunapruk, N., Jones, S. M., Dhippayom, T., \& Sumpradit, N. (2016). Pharmacy practice in Thailand. In: Fathelrahman, A., Ibrahim, M., \& Wertheimer, A. eds. Pharmacy practice in developing countries. 1st edition. London: Academic Press.

51. Pharmaceutical Service Division (PSD), Ministry of Health Malaysia. (2015, June 10). Good pharmaceutical trade practice. Retrieved April 13, 2018, from https://www.pharmacy.gov.my/v2/en/documents/good-pharmaceutical-trade-practice.html-0

52. Pharmaceutical Service Division (PSD), Ministry of Health Malaysia. (2018, September 24). Medicine prices monitoring in Malaysia. Retrieved February 27, 2019, from https://www.pharmacy.gov.my/v2/en/documents/medicine-prices-monitoring-2017.html

\section{Figures}

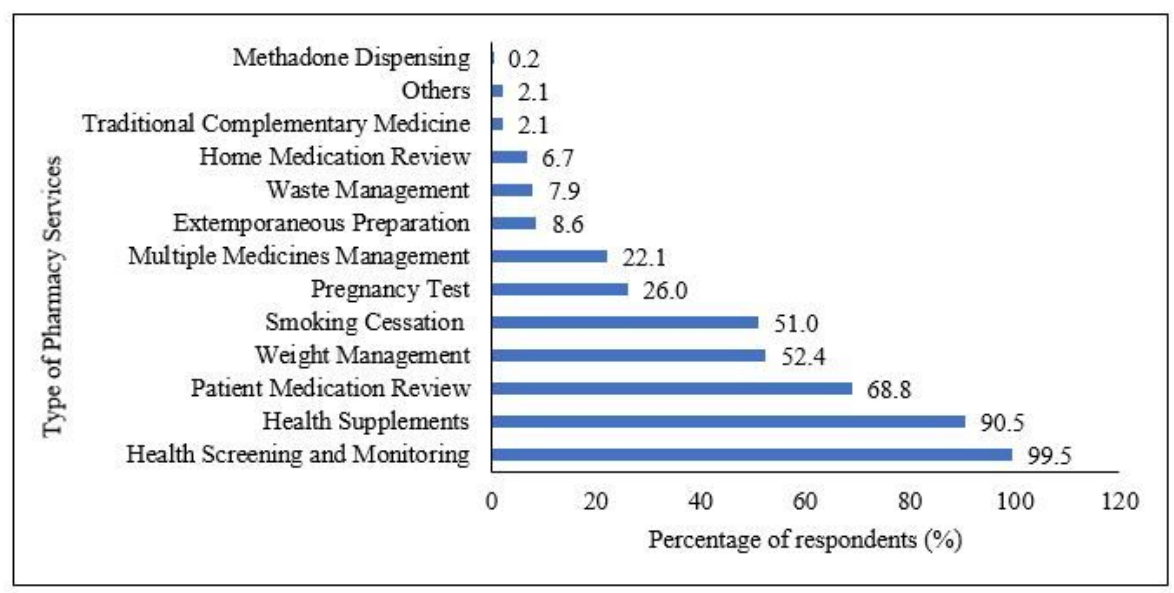

Figure 1

Types of pharmacy services provided regularly other than essential services $(\mathrm{N}=420)$ Note: The percentage may exceed $100 \%$ as the respondents can provide more than one type of service. Others included pain and wound management, counselling on breastfeeding, diet and healthy lifestyle.

Page $15 / 16$ 


\section{Supplementary Files}

This is a list of supplementary files associated with this preprint. Click to download.

- AdditionalFile1PengyeowLoh.pdf

- AdditionalFile2PengyeowLoh.docx 